\title{
PARA CIVILIZAR UMA NAÇÃO: UM ESTUDO SOBRE UM LIVRO ESCOLAR DE EDUCAÇÃO MORAL E CÍVICA EM FLORIANÓPOLIS/1978
}

\section{TO CIVILIZE A NATION: A STUDY UPON A CIVIC EDUCATION TEXTBOOK OF 1978 IN FLORIANOPOLIS, BRAZIL}

\author{
SANTOS, Márcia Regina dos \\ marcia0705@gmail.com \\ UDESC - Universidade do Estado de Santa Catarina \\ CUNHA, Maria Teresa Santos \\ mariatsc@gmail.com \\ UDESC - Universidade do Estado de Santa Catarina
}

\begin{abstract}
RESUMO: A História da Educação em busca de novas perspectivas de investigação passou por um processo de alargamento de fontes, que fez emergir uma grande quantidade de novos objetos de estudo compreendidos como parte da cultura escolar, como os livros escolares. Este artigo objetiva estudar um livro escolar da disciplina de Educação Moral e Cívica utilizado em escolas de Santa Catarina entre as décadas de 1970 e 1980. A partir de exemplar da $5^{a}$ edição do livro de autoria de Benedicto de Andrade, publicado pela Editora Atlas (SP), em 1978, neste estudo serão analisados conteúdos que estavam direcionados para a questão da civilidade, entendida como elemento do processo civilizador na perspectiva trabalhada por Norbert Elias (1993), e proposta para instituir um determinado padrão de convivência social entre os estudantes. O estudo dialoga, igualmente, com os estudos de Roger Chartier (1989; 2014), para compreender a produção material e a circulação, bem como sobre como a civilidade foi dada a ler e representada neste livro escolar.

Palavras-chave: Civilidade. Educação Moral e Cívica. História da Educação. Livros Escolares.

ABSTRACT: The History of Education has been seeking new perspectives to investigate, traversing broadened sources, thus emerging a large amount of new objects of study seen as part of the school culture, such as textbooks. This article aims to study a Civic Education textbook widely utilized in Santa Catarina state schools between the 1970 and 1980 decades. The 5th edition of the book written by Benedicto de Andrade and published by Editora Atlas in 1978 was analyzed in this study in relation to contents on the issue of civility, seen as an element of the civilizing process from Norbert Elias and proposed to institute a certain pattern of social life among students. The study discusses studies by Roger Chartier in a similar way in order to understand the material production and circulation of this textbook, as well as how civility was read and represented in this schoolbook.
\end{abstract}

Keywords: Textbooks. Civic Education. Civility. Education History. 


\section{INTRODUÇÃO}

A pesquisa sobre livros escolares e a História da Educação no Brasil, realizada no âmbito da chamada cultura escolar (JULIA, 2001; VIÑAO FRAGO, 2007), tem despertado muito interesse e proporcionado maior visibilidade dentro do campo da produção historiográfica. Compreender como a escola tornou-se uma instituição de base para a cidadania e a civilidade é ampliar os olhares sobre os processos que forjaram a cultura nacional, em especial a partir da República. $O$ leque de linhas de pesquisas sobre a educação foi aberto de forma que deixou à mostra inúmeras possibilidades, entre elas, o estudo em impressos de uso escolar, os chamados livros escolares (CHOPPIN, 2002) ${ }^{1}$, os quais dão a ver realidades escolares específicas e datadas.

Considerando que, nas últimas décadas, os estudos sobre escolas e sobre a cultura escolar foram relativamente ampliados a partir de um alargamento das fontes e a emergência de uma multiplicidade de objetos para a História da Educação, este artigo objetiva estudar um livro escolar intitulado Educação Moral e Cívica, utilizado em escolas de Santa Catarina entre as décadas de 1970 e 1980, nas aulas da disciplina com o mesmo nome. A partir de um exemplar da $5 .^{a}$ edição desse livro de autoria de Benedicto de Andrade, publicado pela Editora Atlas (SP), em 1978, serão analisados conteúdos que estavam direcionados para a questão da civilidade, entendida como elemento do processo civilizador. Com potencial para instituir determinados padrões de convivência social entre os estudantes, a civilidade é compreendida sob a perspectiva trabalhada nos estudos de Norbert Elias (1993). O estudo dialoga, igualmente, com as propostas de Roger Chartier (1989; 2014) no intuito de empreender sobre a sua produção material, a circulação e, como a civilidade foi dada a ler e representada neste livro escolar.

O livro escolar de Educação Moral e Cívica aqui estudado é compreendido como parte de uma produção específica feita para atender as demandas sociais e culturais do momento em que circulou em escolas brasileiras. Sendo assim, a visão

\footnotetext{
${ }^{1}$ Neste texto será utilizado o termo "livro escolar" (comumente também denominado manual escolar) em consonância com os estudos de Choppin (2002, p. 5-24).
} 


\section{Atos de Pesquisa em Educação - ISSN 1809-0354 \\ Blumenau, v. 12, n.2, p.490- 511, mai./ago. 2017 \\ DOI: http://dx.doi.org/10.7867/1809-0354.2017v12n2p490-511}

sobre a disciplina apresentada pelo autor Benedicto de Andrade diz respeito a um enfoque peculiar inserido no ambiente que determinou a obrigatoriedade do ensino dessa disciplina no currículo escolar. A análise mais detalhada da obra oferece a possibilidade do olhar concentrado sobre aspectos específicos tratados pela referida disciplina. Como o aspecto escolhido para aprofundar a pesquisa foi a civilidade, fezse necessário estabelecer relações com as premissas do processo civilizador de Norbert Elias (1993), o qual discute amplamente as estratégias envolvidas na formação do homem para a vida em sociedade, vislumbrando, assim, pontos de intersecção com os objetivos do ensino da disciplina.

$\mathrm{Na}$ História da Educação, os livros escolares e, igualmente, a imprensa pedagógica (jornais e revistas) vêm recebendo especial enfoque como campo de estudos $^{2}$ por desempenhar papéis multifacetados no processo de escolarização, o qual fez emergir possibilidades de construir histórias sobre prescrições, usos, circulação, apropriação desses materiais escolares. Nas décadas de 1970 e 1980, os livros escolares impressos, especialmente os de Educação Moral e Cívica, configuraram importantes subsídios na construção da civilidade dos sujeitos no período em que o Brasil vivia um regime ditatorial de exceção, advindo do Golpe Civil-Militar de 1964. A escola desempenhou papel fundamental na formação dos alunos que estavam a ser preparados para o futuro. Para tanto:

os jovens, escudados nas forças morais, que devem ser despertadas, senão estimuladas, cujos ideais exprimem inteligentemente o "vir a ser", constiutirão uma geração nova, capaz de dar ao seu povo, à sua gente, possibilidades de um mundo melhor. (ANDRADE, 1978, p. 64).

A Educação Moral e Cívica foi instituída como disciplina obrigatória na cena escolar durante o período ditatorial, momento em que o controle social estava muito presente em todos os círculos. Naquele período, a escola serviu como um dos instrumentos de formação para a construção de um cidadão cordato, respeitoso e patriota (CUNHA, 2011). O Decreto-Lei 869/69 de 12 de setembro de 1969 instituiu a obrigatoriedade da disciplina nos currículos das escolas brasileiras e definiu as

\footnotetext{
${ }^{2}$ Entre os variados estudos que fazem a junção entre História da Educação, Livros Escolares (didáticos, pedagógicos) e Pesquisa, neste texto, destacamos os estudos de BITTENCOURT (2003); GATTI JÚNIOR; FONSECA (2011); FILGUEIRAS (2004) e BASTOS (2010).
} 


\section{Atos de Pesquisa em Educação - ISSN 1809-0354 \\ Blumenau, v. 12, n.2, p.490-511, mai./ago. 2017 \\ DOI: http://dx.doi.org/10.7867/1809-0354.2017v12n2p490-511}

diretrizes da disciplina a partir daquela data, indicando que suas finalidades estavam ligadas ao aspecto civilizador da formação escolar. Instruir os jovens alunos a terem uma postura/conduta pretensamente hegemônica quanto ao outro e quanto ao seu país sinalizava para uma aculturação dos alunos (CHERVEL, 1990), projetando cidadãos responsáveis que saberiam participar da construção do país na perspectiva governamental do progresso, que era uma das metas a ser alcançada. O governo brasileiro, por meio de seu Ministério do Exército, atuava efetivamente na educação ao instituir o ensino obrigatório de uma disciplina de cunho normatizador, conforme dispõe o Decreto-Lei:

Art. $1^{\circ}$ É instituída, em caráter obrigatório, como disciplina e, também, como prática educativa, a Educação Moral e Cívica, nas escolas de todos os graus e modalidades, dos sistemas de ensino no País.

Art. $2^{\circ} \mathrm{A}$ Educação Moral e Cívica, apoiando-se nas tradições nacionais, tem como finalidade:

a) a defesa do princípio democrático, através da preservação do espírito religioso, da dignidade da pessoa humana e do amor à liberdade com responsabilidade, sob a inspiração de Deus;

b) a preservação, o fortalecimento e a projeção dos valores espirituais e éticos da nacionalidade;

c) o fortalecimento da unidade nacional e do sentimento de solidariedade humana;

d) o culto à Pátria, aos seus símbolos, tradições, instituições e aos grandes vultos de sua história. (BRASIL, 1969) ${ }^{3}$.

Os dois primeiros artigos do Decreto-Lei já frisavam o caráter formador da disciplina. O momento conturbado da política brasileira projetou caminhos dentro do sistema de ensino, os quais colaborassem na legitimação das ideias e dos planos de governo. Todas as discussões para instaurar o projeto da obrigatoriedade da disciplina foram amparadas pela necessidade de transmitir valores cívicos e morais considerados apropriados às crianças em idade escolar, de forma que esse conjunto simbólico de conteúdos reverberasse em práticas condizentes à perspectiva de ordem e disciplina projetada pelos dirigentes do país naquele momento. A partir de 1969, a Educação Moral e Cívica se tornou obrigatória e funcionou como um

\footnotetext{
${ }^{3}$ Decreto-Lei $n^{\circ}$ 869, de 12 de setembro de 1969. Dispõe sobre a inclusão da Educação Moral e Cívica como disciplina obrigatória, nas escolas de todos os graus e modalidades, dos sistemas de ensino no País, e dá outras providências. O documento era composto por um total de dez artigos, sendo que o segundo apresentava, no texto integral, oito finalidades.
} 


\section{Atos de Pesquisa em Educação - ISSN 1809-0354 \\ Blumenau, v. 12, n.2, p.490- 511, mai./ago. 2017 \\ DOI: http://dx.doi.org/10.7867/1809-0354.2017v12n2p490-511}

mecanismo de atuação governamental nos currículos escolares, com o objetivo de formar condutas e comportamentos que mantivessem o vínculo entre escola e construção de nacionalidade e do patriotismo.

Até o final da década de 1969 não havia uma formação docente específica para a Educação Moral e Cívica. O Decreto-Lei $n^{\circ}$ 869/69 determinava que a formação de professores (as) se daria no nível universitário e, para os professores do ensino primário, no curso normal. Até que se adquirisse número compatível com a necessidade das escolas, os professores (as) seriam habilitados por um "exame de suficiência" e, enquanto este não fosse concluído, as responsabilidades sobre o ensino da disciplina ficariam a cargo do diretor da escola. Sob nenhuma circunstância o ensino poderia ser negligenciado e, nessa esteira, os livros produzidos para a disciplina se tornariam importantes materiais de apoio na elaboração de planos de ensino e na condução da prática em sala de aula. Desse modo, editoras e livrarias nacionais foram incentivadas a produzir materiais didáticos que dessem suporte ao trabalho docente e, igualmente, compactuassem com a legislação. Para além de um material de apoio, os livros escolares de Educação Moral e Cívica configuravam um relativo protagonismo no ensino da disciplina.

\section{UM LIVRO ESCOLAR COMO AGENTE CIVILIZADOR}

No âmbito da escolarização, o impresso escolar carregava um caráter formador por ser portador de saberes que agregavam na formação intelectual dos alunos, facilitando assim 0 seu ingresso nas cadeias entrelaçadas de interdependência (ELIAS, 1993), necessárias ao convívio social. Os conteúdos selecionados tinham o intuito de adestrar para os princípios de organização e higiene, nos primeiros anos de escolarização, e de civilizar e normatizar, nos últimos anos do fundamental e no secundário. Dessa maneira, os impressos escolares colaboravam com a concretização de projetos governamentais nacionais que, por meio da educação, instituíam práticas e padrões desejados.

Os livros de Educação Moral e Cívica, em especial os produzidos a partir da obrigatoriedade do ensino pelo Decreto-Lei $n^{\circ}$ 869/69, constituem objetos de estudo 


\title{
Atos de Pesquisa em Educação - ISSN 1809-0354 \\ Blumenau, v. 12, n.2, p.490-511, mai./ago. 2017 \\ DOI: http://dx.doi.org/10.7867/1809-0354.2017v12n2p490-511
}

para a compreensão de um estatuto social correspondente a um tempo e espaço específicos. Além de fazer circular entre os cidadãos/estudantes os ideais políticos sob os quais o país estava sendo conduzido, eram portadores de um caráter civilizador, o qual permeava as páginas de normas e condutas. Eram instrumentos de formação que continham as prescrições subjetivas das mudanças de comportamento.

\begin{abstract}
Aprende-se o hábito, forma-se o hábito, adquire-se o hábito. É um novo modo de agir, de pensar, de sentir, que se insere em nós, uma nova maneira de reagir em face do mundo, que devemos aprender, que aprendemos sem querer, que fixamos, que esquecemos também. Organizase no sitema nervoso, cria vias de reação prontas e rápidas, permite-nos ação perfeita, quase sem a consciência delas. (ANDRADE, 1978, p. 70).
\end{abstract}

Era uma preocupação fazer chegar até a juventude de estudantes esses códigos de civilidade que ultrapassavam o ensino intelectual e vislumbravam a formação do ser, no qual se inscrevia "um cego aparelho automático de autocontrole" (ELIAS, 1993, p. 196). Como o ensino era dimensionado pela disciplina e pela prática educativa, os ditos novos hábitos eram disseminados pela leitura da teoria e cultivados pelo estímulo da prática. As lições incorporadas à vivência poderiam evitar certos tipos de transgressões ao comportamento esperado, construindo uma sociedade mais homogênea e gerenciável do ponto de vista do governo ditatorial.

Inserido nos conteúdos lecionados nessa disciplina, circulava o ideal social que demandava daquele momento histórico, atendendo ao processo de (re) configuração de uma sociedade que se adaptava ao sistema ditatorial. É importante salientar que não se ignora aqui o fato de que as imposições sociais, culturais, escolares, se estabelecem com tensões e resistências, porém, o foco de análise está restrito aos conteúdos prescritivos. Os livros da disciplina de Educação Moral e Cívica, produzidos nas décadas de 1960 e 1970, são exemplos da utilização dos impressos como instrumentos de formação de conduta e civilidade, bem como, o exemplar do livro escolar alvo deste estudo, do qual foram retirados os exemplos que pretendem dialogar com as questões selecionadas. 


\section{Atos de Pesquisa em Educação - ISSN 1809-0354 \\ Blumenau, v. 12, n.2, p.490-511, mai./ago. 2017 \\ DOI: http://dx.doi.org/10.7867/1809-0354.2017v12n2p490-511}

Trata-se do livro escrito por Benedicto de Andrade, cujo título traz o próprio nome da disciplina - Educação Moral e Cívica - publicado em São Paulo pela Editora Atlas e, em 1978, encontrava-se em 5. ${ }^{a}$ edição revisada e aumentada. Sobre o autor, as informações encontradas, além de sua patente militar - General Benedicto de Andrade, indicam que foi professor catedrático na Academia Militar das Agulhas Negras, lecionou a disciplina de História da Educação no Ginásio e Escola Normal Santa Ângela e Técnicas Comercias na Escola Técnica do Comércio Dom Bosco, ambas em Resende, no estado do Rio de Janeiro. O livro escolar apresenta dois prefácios assinados pelo autor, relativos à $1 .^{a}$ e $2 .^{a}$ edições. O prefácio à $1 .^{a}$ edição é datado do ano de 1970, fato que permite intuir que sua primeira edição tenha sido publicada logo após a regulamentação da disciplina em 1969.

Como protocolo de leitura, a capa de um livro tem a função de sedução sobre o leitor, é o convite à leitura interior que se anuncia pelo contato visual. "Não há compreensão de um escrito, qualquer que ele seja, que não dependa das formas através das quais ele chega ao seu leitor" (CHARTIER, 1989, p. 127) e, a capa faz essa inicial interlocução. Nesse caso, a obra apresentava o Monumento à Independência ${ }^{4}$ (Figura 1). A imagem impressa ostenta o simbolismo dos grandes atos heroicos e das conquistas do país. A mensagem iconográfica propõe despertar uma sensibilidade para a leitura e, a escolha do tema, das cores e das letras faz parte das estratégias editoriais e visuais que constituem essa relação entre o livro e o leitor.

Figura 1: Capa do livro de Benedicto de Andrade (1978)

\footnotetext{
${ }^{4}$ Está localizado às margens do riacho Ipiranga, e foi construído em 1922 para comemorar o centenário da Independência do Brasil. Encontra-se no lugar onde conta-se que D. Pedro I gritou: 'Independência ou Morte'; proclamando o Brasil livre de Portugal. O monumento é em bronze e granito, foi idealizado e executado pelo escultor italiano Ettore Ximenes. Para reforçar ainda mais o significado daquele local como o do nascimento da nação brasileira, foi instalada uma cripta que funcionaria como Capela Imperial, construída em 1952 para abrigar os restos mortais de D. Pedro I, de sua primeira esposa, D. Leopoldina, e também de sua segunda esposa, D. Amélia, todos trasladados de Lisboa. O Monumento à Independência também abriga em seu interior, desde 2001, um espaço de exposições administrado pela Divisão de Iconografia e Museus do Departamento do Patrimônio Histórico. Disponível em: http://www.prefeitura.sp.gov.br/cidade/secretarias/cultura/patrimonio_historico/adote_obra/index.php? $\mathrm{p}=4539$. Acesso em: 10 out. 2014.
} 


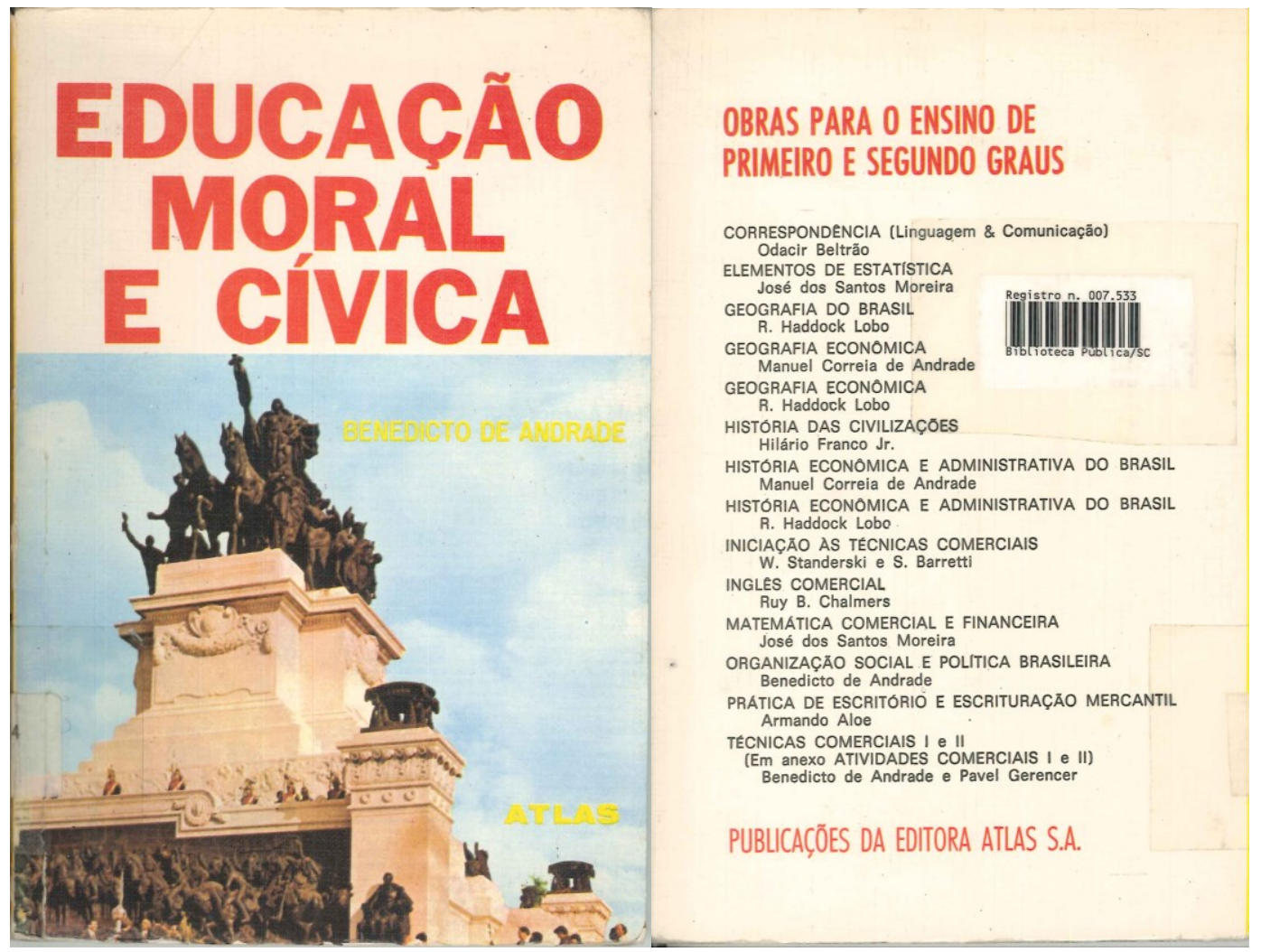

Fonte: ANDRADE, 1978.

A capa e a diagramação foram assinadas por Pavel Gerencer, possivelmente um profissional destacado para cuidar dessa parte do processo editorial, visto que, no prefácio à $2^{a}$ edição, o autor faz um agradecimento, identificando-o como funcionário da Editora Atlas. O estudo de Gatti Jr. (2004) sobre livros didáticos de História infere que nas décadas de 1960 e 1970 uma nova configuração editorial surge e modifica o sistema de produção. Os livros para uso escolar tiveram significativa demanda e as editoras precisaram remodelar seus esquemas de trabalho. Uma mudança considerada relevante foi a incorporação de uma equipe técnica que atuaria na organização dos livros. Os indícios permitem pensar que o livro de Andrade foi uma produção que envolveu uma equipe para tratar das questões gráficas e textuais, pois o agradecimento referia-se à coleta de elementos para a feitura do livro e a revisão do mesmo, demonstrando a colaboração em várias etapas da edição.

O livro escolar, ao longo de suas 215 páginas, desenvolveu uma organização extremamente minuciosa quanto à sistematização dos conteúdos. O sumário (Figura 
2) apresentou-se com 9 unidades, 26 capítulos, 52 subcapítulos e 9 divisões dos subcapítulos, oferecendo informações muito detalhadas a respeito dos conteúdos que seriam tratados. Cada um dos conteúdos, organizados pelos itens do sumário, era apresentado de forma detalhada, facilitando o direcionamento do leitor. O livro dispunha de outros elementos para guiar a leitura. Além de uma epígrafe, havia dois prefácios, como já foi mencionado, instruções de uso, três apêndices e bibliografias parciais ao longo dos conteúdos e geral ao final do livro. O autor utilizou um recurso gráfico/textual como estratégia de síntese pontual sobre as unidades estudadas. A nomenclatura utilizada para essa seção também foi Sumário (Figura 3), porém sua localização é ao final de cada uma das unidades. Na sequência dessa seção do livro havia uma listagem chamada Temas para estudo, com sugestões de pesquisa e aprofundamento, e os Trabalhos práticos, compostos de questões de interpretação para o melhor entendimento e fixação dos conteúdos. 
Atos de Pesquisa em Educação - ISSN 1809-0354

Blumenau, v. 12, n.2, p.490- 511, mai./ago. 2017

DOI: http://dx.doi.org/10.7867/1809-0354.2017v12n2p490-511

Figura 2: Sumário geral do livro de Andrade

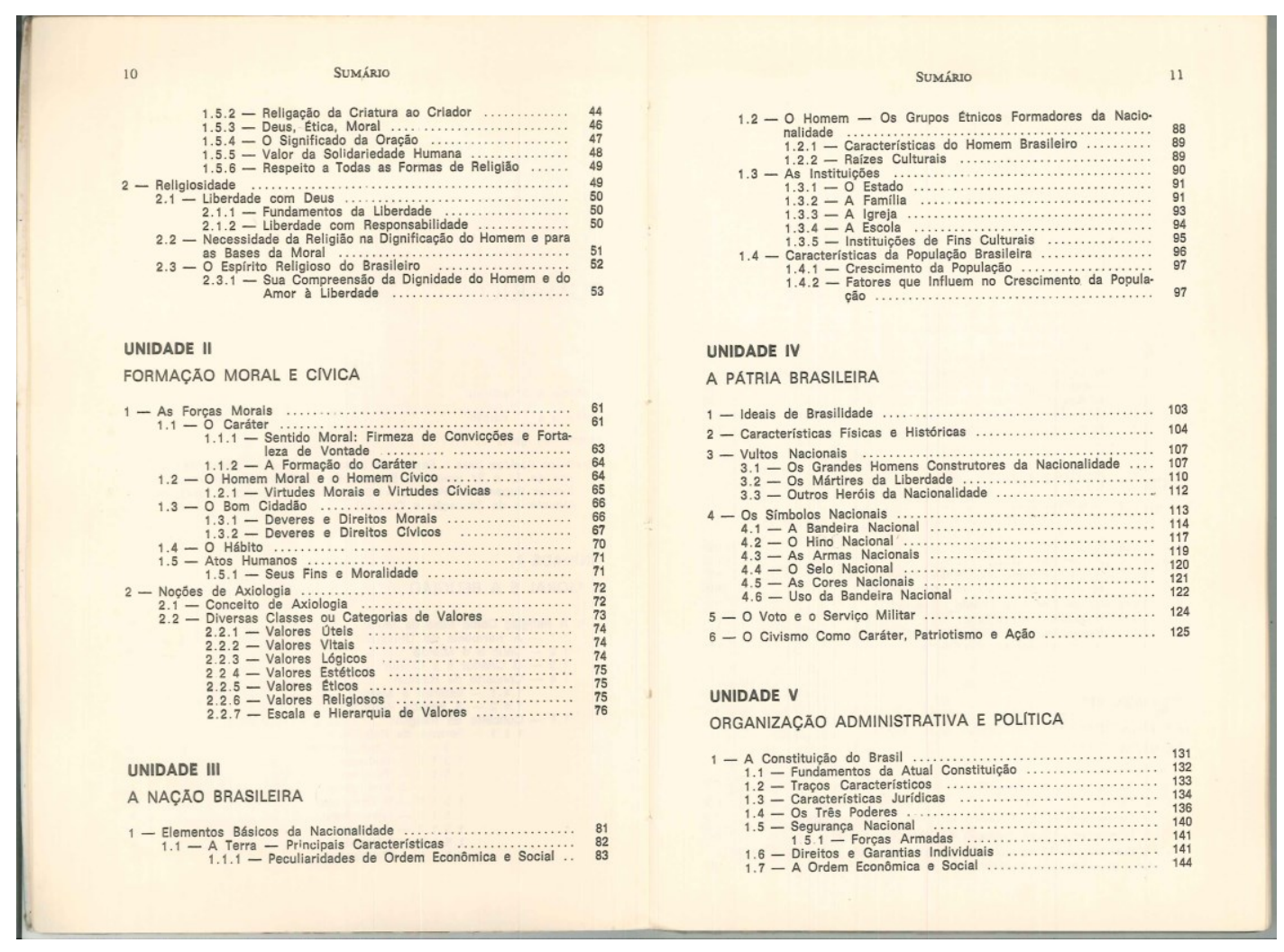

Fonte: ANDRADE (1978, p. 10-11).

Figura 3: Sumário da unidade no livro de Andrade 


\section{Atos de Pesquisa em Educação - ISSN 1809-0354 \\ Blumenau, v. 12, n.2, p.490-511, mai./ago. 2017 \\ DOI: http://dx.doi.org/10.7867/1809-0354.2017v12n2p490-511}

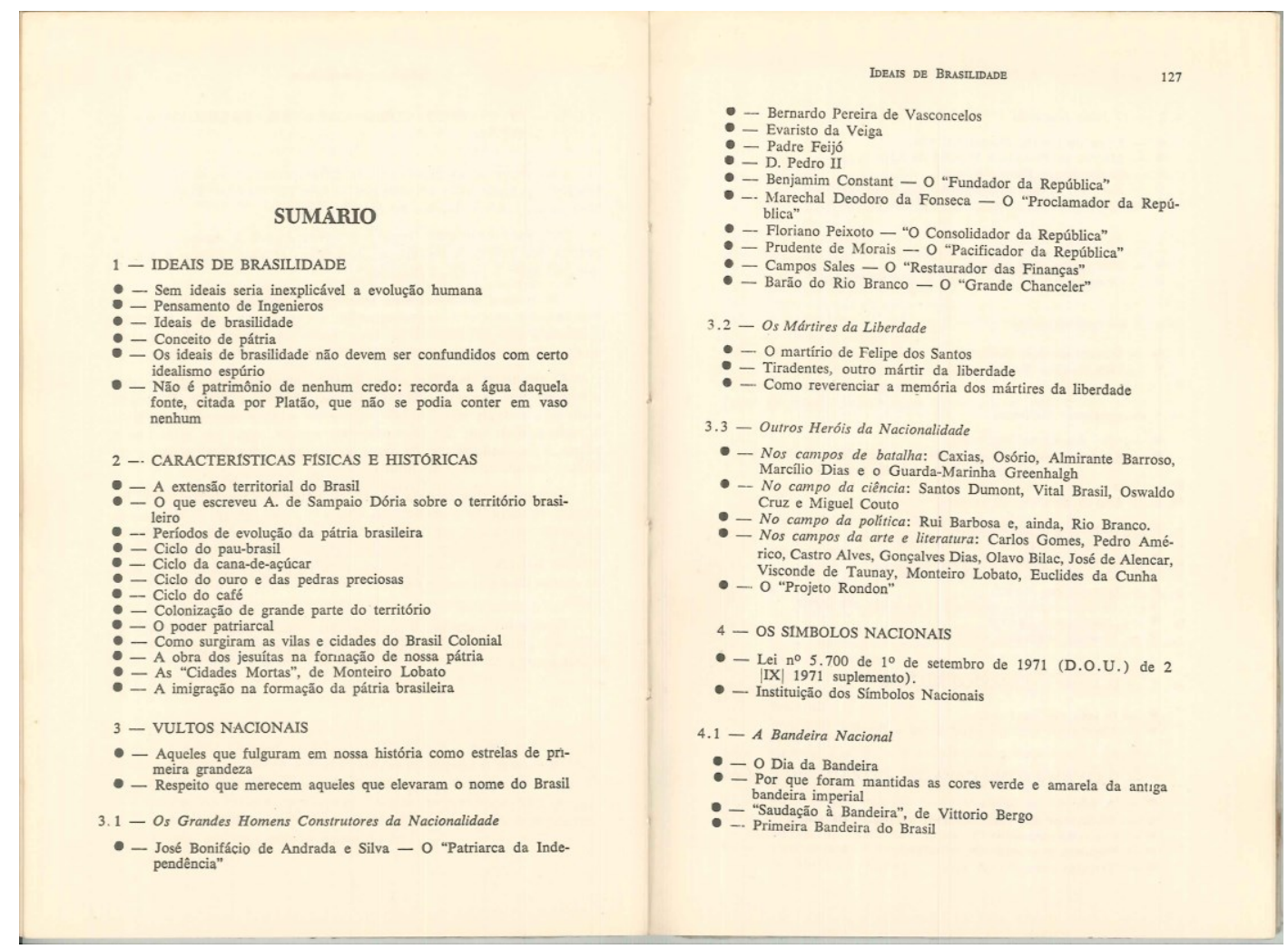

Fonte: ANDRADE (1978, p.126-127).

Segundo os estudos de Filgueiras (2006), esse livro foi elaborado atendendo as prescrições curriculares para o ensino médio e as orientações gerais da Comissão Nacional de Moral e Civismo $(\mathrm{CNMC})^{5}$ e do Ministério da Educação e Cultura (MEC). No entanto, o exemplar não apresenta a cópia do documento de autorização para produção, como ocorria com outros livros escolares da mesma disciplina. Como forma de legitimação dos saberes veiculados, algumas editoras imprimiam nas primeiras páginas uma reprodução do documento emitido pela CNMC e o MEC, destacando a recomendação para a produção e circulação da obra. Apesar de não ser este o caso do livro de Andrade, logo após os dois prefácios, se

\footnotetext{
${ }^{5}$ Órgão criado no Ministério de Educação e Cultura, diretamente subordinado ao Ministro de Estado. A comissão era integrada por nove membros, brasileiros, nomeados pelo Presidente da República, por seis anos. Suas atribuições se relacionavam ao fomento de uma cultura ancorada na moral e no civismo e extrapolava o âmbito escolar, executando ações nas esferas profissionais e midiáticas. Tinha como principais funções auxiliar o Conselho Federal de Educação na elaboração de currículos e programas de ensino, escolher, aprovar ou vetar livros didáticos, atuar junto a organizações sindicais, instituições e órgãos formadores de opinião e difusores culturais com vistas a promover o desenvolvimento e manutenção de atividades relacionadas com o ensino da Educação Moral e Cívica e com o espírito do Decreto-Lei 869/69. (FILGUEIRAS, 2006). (BRASIL, 1969).
} 


\section{Atos de Pesquisa em Educação - ISSN 1809-0354 \\ Blumenau, v. 12, n.2, p.490-511, mai./ago. 2017 \\ DOI: http://dx.doi.org/10.7867/1809-0354.2017v12n2p490-511}

encontra o item Orientação Geral, o qual trata, segundo o autor, de "definir a amplitude e o desenvolvimento dos Programas de Educação Moral e Cívica" (ANDRADE, 1978, p. 19). O item reproduz um documento elaborado pela CNMC e a Portaria $\mathrm{n}^{\circ}$ 505, de 22 de agosto de 1977, do MEC, intitulada "Diretrizes básicas para o ensino de Educação Moral e Cívica, nos cursos de $1^{\circ}$ e $2^{\circ}$ graus, e de Estudos de Problemas Brasileiros, nos cursos superiores" (ANDRADE, 1978, p. 23). A presença dos documentos nas primeiras páginas indica a preocupação em explicitar a adequação do livro, mas, também, a possibilidade de não ter passado pelo crivo da CNMC e sua direta autorização para produção.

Os conteúdos foram elaborados destacando a importância de assumir compromissos com a sociedade e com as virtudes morais e éticas defendidas pela proposta da disciplina. O texto de Benedicto de Andrade dialoga com seu interlocutor argumentando sobre a responsabilidade do mesmo diante de seu país, e sobre a necessidade de integração aos círculos sociais. Cada indivíduo era entendido como peça fundamental de uma engrenagem social que conduziria o país ao desenvolvimento e ao progresso. Antes mesmo de ser cidadão - pois esta condição estava vinculada à idade de dezoito anos e a votação nas eleições -, o aluno internalizava o compromisso de ser um homem moral e um homem cívico, que Andrade (1978, p. 64) explica da seguinte forma: "Homem moral é aquele que na prática dos preceitos morais, se dignifica. Homem cívico é aquele que, no amor à pátria, a dignifica".

Era uma cidadania pensada para atender as demandas daquele momento do país. Os valores exaltados nos livros tinham um protagonismo na configuração da sociedade.

\footnotetext{
Hierarquização dos valores:

$1^{\circ}$ Valores Religiosos;

$2^{\circ}$ Valores Éticos;

$3^{\circ}$ Valores Estéticos;

$4^{\circ}$ Valores Lógicos;

$5^{\circ}$ Valores Vitais;

$6^{\circ}$ Valores Úteis. (ANDRADE, 1978, p. 74).

Escala e Hierarquia de Valores

Há evidentemente uma hierarquia entre os valores mencionados, que vai crescendo do útil ao religioso. Assim, entre salvar a própria vida (valor vital)
} 


\author{
Atos de Pesquisa em Educação - ISSN 1809-0354 \\ Blumenau, v. 12, n.2, p.490- 511, mai./ago. 2017 \\ DOI: http://dx.doi.org/10.7867/1809-0354.2017v12n2p490-511
}

\begin{abstract}
e perder a honra (valor moral ou ético), ou abjurar uma verdade religiosa, muitos, hierarquicamente, preferiram os valores superiores e desprezaram mesmo o valor vital fundamental, preferindo a morte. Verificamos isto na história do cristianismo, que conta milhares de mártires. Dentro desta escala e desta hierarquia desaparecem e surgem novos valores, por que o meio em que vive o homem apresenta substanciais modificações, determinando novas necessidades, e os objetos que satisfazem se constituem em valores. (ANDRADE, 1978, p. 76).
\end{abstract}

Os valores hierarquizados remetem a uma axiologia e pretendiam representar a evolução do desenvolvimento dos indivíduos, no qual era imprescindível que subjetividades como religião e ética fossem administradas em busca da homogeneidade. É importante salientar que essa não é uma via de mão única, pois, as concepções do Estado sobre os cidadãos e a cidadania não são necessariamente as que circulam no meio social, portanto os discursos apresentados davam a ver as prescrições oficiais, mas a circulação, o uso destes discursos era conflituoso e negociava constantemente com as manifestações sociais que interagiam com a cultura escolar.

Os conteúdos propunham edificar uma responsabilidade mútua entre o cidadão, a comunidade e as instituições, bem como, atendiam as prescrições que qualificavam a formação do bom cidadão como conhecedor dos seus direitos e deveres. A partir do momento que fosse tomada essa consciência, estabelecia-se o limite a que essas aquisições estavam submetidas dentro da sociedade, observando-se bem mais os deveres do que os direitos. Em que pese serem leituras institucionalizadas, produzidas para fim de aprendizado, os livros escolares de Educação Moral e Cívica carregam as marcas de vivências sociais pelo fato de transmitirem saberes de um tempo e, são, concomitantemente, produtor e produto cultural. No momento de sua produção eram observadas as normas que partiam das concepções prescritas, porém, ao longo de seu uso, denunciavam recuos e aproximações quanto àquelas prescrições. Este intervalo que se instala entre o que foi produzido e o que foi entendido pode ser interpretado como o espaço das representações formuladas por um grupo em certo meio e tempo social.

São estes esquemas intelectuais incorporados que criam as figuras graças às quais o presente pode adquirir sentido, o outro tornar-se inteligível e o espaço ser decifrado. [...] As percepções do social não são de forma alguma 


\section{Atos de Pesquisa em Educação - ISSN 1809-0354 \\ Blumenau, v. 12, n.2, p.490-511, mai./ago. 2017 \\ DOI: http://dx.doi.org/10.7867/1809-0354.2017v12n2p490-511}

discursos neutros: produzem estratégias e práticas (sociais, escolares, políticas) que tendem a impor uma autoridade à custa de outros, por elas menosprezados, a legitimar um projecto reformador ou a justificar, para os próprios indivíduos, as suas escolhas e condutas. (CHARTIER, 1989, p. 17).

A civilidade projetada no livro escolar visava à transformação e incorporação de novos esquemas intelectuais que se estabelecessem como práticas. Relacionada à ideia de autocontrole exigia um domínio mais efetivo das emoções por parte dos indivíduos - um abrandamento das pulsões, no qual,

O controle mais complexo e estável da conduta passou a ser cada vez mais instilado no indivíduo desde os primeiros anos, como uma espécie de automatismo, uma auto compulsão à qual ele não poderia resistir, mesmo que desejasse. (ELIAS, 1993, p. 196).

A premissa de formar para a sociedade e para a vida egressa selecionava os argumentos mobilizados na elaboração de livros para a disciplina de Educação Moral e Cívica. O artigo $1 .^{\circ}$ do Decreto-Lei 869/69 definia que a disciplina seria ensinada como fundamento teórico e como prática educativa. Os saberes escolhidos para a produção dos livros escolares projetavam a extensão de seu uso prevendo a educação além da sala de aula, nas famílias e nos círculos sociais dos alunos. Intuía-se que as transformações comportamentais promovidas no ambiente escolar ressoassem como exemplos amplificando a proposta de ensino. "Uma forma de disciplinar as mentes pela prescrição de normas de comportamento sociáveis" (CUNHA, 2013, p. 143) e, dessa forma, normalizar uma sociedade que atravessava um período conturbado de tensões sociopolíticas. Era a idealização de uma prática no presente, que reverberasse no comportamento futuro dos leitores. A criação de uma sensibilidade para o coletivo, utilizando o elemento simbólico de união entre todos, que era a pátria.

Utilizando uma sistematização a qual lembra sobremaneira os mandamentos propostos por preceitos religiosos, o autor elabora uma lista que contempla os principais critérios, segundo sua seleção, para que o civismo seja uma vivência dos cidadãos. 


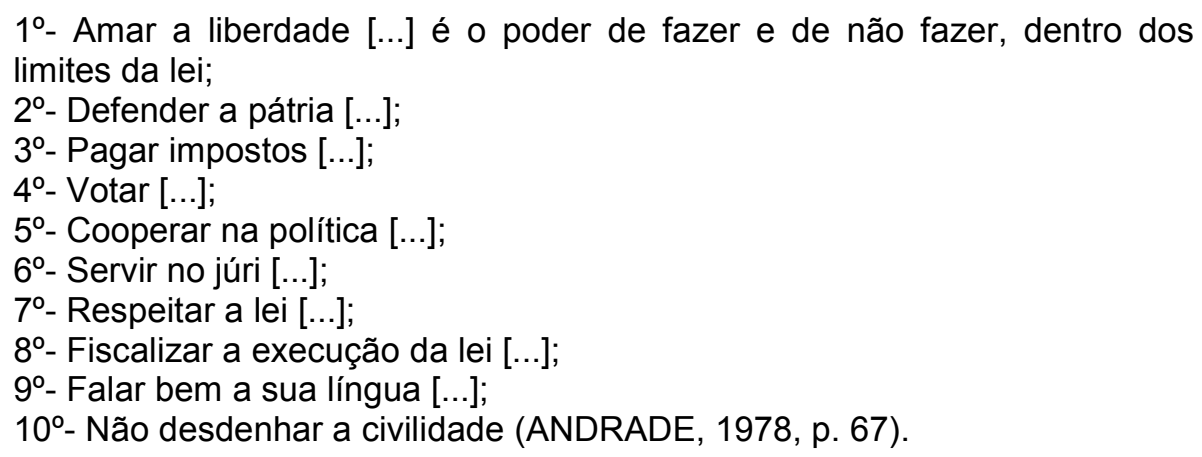

Na leitura do primeiro item observa-se que o leitor tem a impressão de estar em contato com uma proposta de resguardo dos seus direitos individuais. Ao final do item ressalta-se a observação "dentro dos limites da lei", então o Estado se faz presente delimitando a liberdade do cidadão. Os próximos itens fazem alusão à obrigação do cidadão de contribuir com a estrutura social que organiza o país. Elementos importantes na questão da manutenção da ordem, pois dividindo a responsabilidade com cidadãos, o Estado agregava aliados na solidificação do sistema de governo.

A leitura e interpretação levam a perceber a intencionalidade sem a ilusão do doutrinamento, para além disso, entender o texto como elemento de uma realidade datada e contextualizada. Os livros se valiam de sua autoridade de escolares e de estratégias de pertencimento para realçar ao leitor as informações que melhor se inscreviam no projeto oficial de governo e de reformulação social. Consideravelmente, estão ali as representações de uma sociedade em fase de mudança e adaptação. A análise dos escritos expõem as tensões em torno da formação das estruturas intelectuais, tanto individuais como coletivas. As relações entre o mundo do texto e o mundo do leitor (CASTILLO GÓMEZ, 2002) fazem emergir as concepções que a sociedade, especialmente os sistemas educativos, estava construindo sobre as prescrições oficiais.

O décimo item dos Direitos e deveres cívicos remete à educação no espaço dos grupos menores, das vivências mais íntimas. Norbert Elias alerta que as mudanças na dinâmica social se impõem primeiramente por ações individuais. Somente depois de um tempo, disseminadas e reproduzidas constituem-se no que o autor chamou de "anelos humanos entrelaçados" (ELIAS, 1993, p. 194). Portanto, 


\section{Atos de Pesquisa em Educação - ISSN 1809-0354 \\ Blumenau, v. 12, n.2, p.490-511, mai./ago. 2017 \\ DOI: http://dx.doi.org/10.7867/1809-0354.2017v12n2p490-511}

verificar a preocupação com os casos de comentários e maledicências na formação escolar sinaliza a produção institucionalizada de novas sensibilidades no trato com o outro e com os grupos sociais. O exemplo em destaque permite uma maior visibilidade acerca destas questões.

$10^{\circ}$ Não desdenhar a civilidade

Este dever envolve dois elementos, um negativo e outro positivo. O negativo é não se intrometer ninguém na vida íntima dos outros. Não que deva a gente abster-se de comentários sobre tudo e sobre todos. Se não degenerar em maledicência, este comentário importa no compromisso, por quem o faz, de não incidir no mesmo ato que condena. É uma espécie de lição de coisas de moral prática. Mas nunca intrigar, meter-se na vida íntima dos outros, promovendo a cizânia, que agrava as durezas já inevitáveis da vida. O elemento positivo está na gentileza e sinceridade do trato, na lealdade e distinção com que se satisfazem as próprias aspirações, em meio dos egoísmos contrários. Não está na cortesanice dos áulicos, na pragmática da hipocrisia, em que há risos alvares de lacaio. Não está na frase rebuscada de uma polidez de falsa fé. Mas reside, essencialmente, na sinceridade e tolerância que o dinheiro não compra, mas a educação prodigaliza. Só uma intensa cultura, no estudo e no convívio dos bons, pode transfigurar os instintos malsãos, hereditários em todos, na firmeza de uma vida vitoriosa que não agride, antes constrói para o futuro. A civilização de um povo, na polidez de suas maneiras, é a fina flor entre os mais sublimes ideais da pátria (ANDRADE, 1978, p. 69).

O texto relativo à $10 .^{a}$ regra dos Direitos e deveres cívicos é um exemplo da argumentação utilizada pelo autor ao discutir o comportamento cotidiano esperado dos alunos em formação como futuros cidadãos. A ideia foi construída de maneira que tenha um efeito restritivo a certas atitudes que são inerentes ao convívio diário, promovendo certo constrangimento àquelas práticas que, segundo o texto, desdenham da civilidade. Estimulando uma progressiva diminuição de determinadas práticas, a recomendação do autor Benedicto de Andrade encontra referência nos estudos de Elias (1993, p. 202, grifo do autor), para quem:

Desde o começo da mocidade, o individuo é treinado no autocontrole e no espírito de previsão dos resultados de seus atos, de que precisara para desempenhar funções adultas. Esse autocontrole é instilado tão profundamente desde a tenra idade que, como se fosse uma estação de retransmissão de padrões sociais, desenvolve-se nele uma auto supervisão automática de paixões, um "superego" mais diferenciado e estável, e uma parte dos impulsos emocionais e inclinações afetivas sai por completo do alcance direto do nível da consciência. 
O texto foi construído de forma que os leitores possam vislumbrar a dualidade das situações e das consequências de suas atitudes. Escrevendo os aspectos positivos e negativos sobre a regra dos Direitos e deveres cívicos, o autor expõe o veto explicando suas intercorrências de maneira que as possibilidades podem ser compreendidas e até analisadas pelo leitor. Ao ler "não que deva a gente abster-se de comentários sobre tudo e sobre todos", entende-se que a condenação aos comentários abre precedentes para o uso da escolha individual, porém, na sequência, quando explica que não se pode "degenerar em maledicência" e nem "intrigar", ou "meter-se na vida íntima dos outros, promovendo a cizânia", alerta para a responsabilidade que se deve ter ao proferir suas considerações sobre algum assunto. De certa maneira, a atuação do indivíduo é colocada como interdependente ao grupo em que está inserido, no qual seu comportamento é atuante na imagem que constrói sobre a sociedade (ELIAS, 1993).

Quando o autor afirma que o valor da vida em sociedade "não está na cortesanice dos áulicos, na pragmática da hipocrisia, em que há risos alvares de lacaio" (ANDRADE, 1978, p. 69), além do vocabulário rebuscado, é possível perceber que procura instruir para que haja gentileza e cortesia autênticas, que não se vinculem ao favorecimento ou interesse, pois, o intuito é de formar o caráter e os hábitos, para promover uma convivência cordial e pacífica sempre colocada de forma maniqueísta, dual. É importante frisar que no período ditatorial, esse tipo de sociedade seria mais fácil de ser administrada, evitando divergências e conflitos. Estimulando um tipo de consciência coletiva, era uma forma de transferir o campo de batalha social para dentro dos indivíduos (ELIAS, 1993) em forma de autocontrole.

A configuração do texto atenta para os aspectos que vão além das questões ufanistas de doutrinação, geralmente associadas à disciplina. O autor preocupou-se em construir argumentos de persuasão que incorporassem o leitor como sujeito dessa formação. Não é possível pensar que os ensinamentos eram passivamente apropriados, pois a leitura é um ato íntimo que proporciona produções de sentido únicas (CHARTIER, 1989), porém é possível considerar que o aspecto formador 


\section{Atos de Pesquisa em Educação - ISSN 1809-0354 \\ Blumenau, v. 12, n.2, p.490-511, mai./ago. 2017 \\ DOI: http://dx.doi.org/10.7867/1809-0354.2017v12n2p490-511}

apresentava elementos peculiares ao objetivo da disciplina de preparar os cidadãos do futuro com uma determinada diretriz.

As leituras oferecidas no livro de Educação Moral e Cívica construíam uma relação entre o comportamento individual e o social. Entendia-se necessário instruir os leitores a incorporarem os mais adequados comportamentos, segundo as exigências sociais do momento. Os saberes da disciplina adquiriam contornos de adestramento/doutrinação para facilitar a organização da vida em sociedade e instituir o respeito ao outro e às instituições. O amor à pátria estava inscrito na relação com o outro e com a comunidade, por isso se projetava no comportamento individual a grandeza do povo e do país.

Se o ideal do homem de fé sincera é reverenciar o Senhor nas homenagens do culto, e consagrar-lhe o espírito na prática da moral religiosa, isto também se dá na religião da pátria. Há nela três elementos que a fundamentam: o caráter, o patriotismo e a ação. [...] O patriotismo que interessa diretamente o sentimento cívico e o faz vibrar. Celebram-se os fatos nacionais. Institui-se o culto dos heróis. Cantam-se canções de guerra. Descobrimo-nos todos, quando toca o hino. Rezam-se orações à bandeira. Um toque de clarim ecoa em nosso espírito, como um canto de alvorada para a glória (ANDRADE, 1978, p. 125).

Comparando o culto à pátria ao culto religioso, o autor destaca os sentimentos evocados pelas simbologias e subjetividades que se inscrevem na relação pátria-cidadão. O patriotismo figura no mesmo patamar de importância que a fé religiosa, exaltando o amor exacerbado e o apelo emotivo pelas instituições e construções históricas. Os símbolos nacionais apresentam-se como objetos que beiram o sagrado, e o apreço dedicado confere satisfação metafísica. O cidadão patriota não deve cultivar apenas o respeito, deve nutrir os sentidos mobilizados pelas práticas, estabelecer o vínculo sensorial que a disciplina estimula a partir dos princípios que significaram a sua concepção.

\section{CONSIDERAÇÕES FINAIS}

O olhar específico sobre esse tipo de artefato da cultura escolar contribui para cotejar as ações que circulam entre o "dito" e o "feito" na escola. Identificar os 


\section{Atos de Pesquisa em Educação - ISSN 1809-0354 \\ Blumenau, v. 12, n.2, p.490-511, mai./ago. 2017 \\ DOI: http://dx.doi.org/10.7867/1809-0354.2017v12n2p490-511}

aspectos mais relevantes sobre a formação dos sujeitos de um tempo, perceber a relação entre a escola e a sociedade dá a ver a ação da escolarização no processo civilizatório contínuo que perpassa os tempos e os espaços. A instituição da obrigatoriedade da disciplina de Educação Moral e Cívica através do Decreto-Lei 869/69 foi um dos pontos de ligação entre a educação formal e o estabelecimento de uma cultura dita cívica. Os princípios sobre os quais a disciplina amparou-se apresentaram o ideal de configurar uma sociedade de acordo com as políticas socioculturais desenvolvidas naquele período.

$\mathrm{Na}$ organização das disciplinas escolares, a construção da civilidade e da conduta foi associada a algumas áreas de conhecimento. "As disciplinas escolares estão no centro desse dispositivo. Sua função consiste em cada caso colocar um conteúdo de instrução a serviço de uma finalidade educativa" (CHERVEL, 1990, p. 188). A Educação Moral e Cívica no currículo escolar brasileiro, decretada obrigatória em 1969, corroborou com o processo de adaptação dos cidadãos a uma realidade desejada e imposta pelo período de ditadura que se ligava a uma orientação política e cívica.

A análise do livro escolar de Benedicto de Andrade permitiu vislumbrar ideais civilizadores que vão além da construção da obediência e da passividade. Apesar do momento de tensão política, os planos de governo lançaram mão de projetos formadores, onde a necessidade de convivência e relacionamento nortearam as condutas. Os conteúdos organizados no livro primavam pela edificação do que se entendia como o bom cidadão. A expressão dos conceitos sobre a moral e o civismo procurava remeter às responsabilidades do indivíduo perante o meio em que convive e perante o desenvolvimento de sua sociedade. A hierarquização dos valores a serem priorizados fazia referência ao desenvolvimento do ser e, dessa forma, podese pensar no livro escolar como se fosse um manual comprometido com o processo civilizacional escolarizado.

Independente de ser uma disciplina norteada pelos preceitos ditatoriais vigentes no país da década de 1960, foi possível identificar princípios gerais de convivência atribuídos às sociedades ditas civilizadas. Benedicto de Andrade expressou aspectos que definiam o homem moral e o homem cívico como 


\section{Atos de Pesquisa em Educação - ISSN 1809-0354 \\ Blumenau, v. 12, n.2, p.490-511, mai./ago. 2017 \\ DOI: http://dx.doi.org/10.7867/1809-0354.2017v12n2p490-511}

habilidades que eram importantes à construção social. Sendo as representações constituídas como presença de algo que está ausente (CHARTIER, 1989), as noções de civilidade empreendidas ao longo das páginas estavam simbolicamente prescrevendo uma cultura a ser apropriada. Era o Estado presente na vivência escolar, preparando cidadãos para o futuro da pátria. Os ensinamentos dispostos nos livros projetaram as representações de um grupo específico em situação datada que foram discutidas neste estudo, mas é necessário enfatizar que essa é apenas uma das possibilidades que pairam sobre os escritos.

De certa forma, a apresentação das leituras cumpriu os objetivos de sua prescrição formativa, tendo em vista o que determinava o Decreto-Lei 869/69, propulsor da produção desse livro escolar que está em desuso na escola e é objeto, agora, de estudos. Para além da perspectiva de formação, as estratégias textuais do autor oferecem possibilidade de reflexão e debate sobre as culturas escolares geradas a partir das prescrições, sobre a extensão do ensino formal ao disseminar outros padrões de comportamento e inclusive sobre o lugar dos livros escolares como portadores de referências socioculturais de um período determinado.

Os limites da pesquisa não permitem afirmar como foi feita a leitura ou mesmo de que maneira os textos foram recebidos, porém, o estudo permitiu sinalizar para a utilização do livro escolar como um elemento prescritivo de práticas de civilidade. O exame dessa fonte privilegiada da cultura escolar viabiliza percorrer novos caminhos para a pesquisa histórica no campo educacional. Da mesma forma que serviram de suporte para os saberes da extinta disciplina de Educação Moral e Cívica, os livros escolares continuam cumprindo um relevante papel na formação escolar. Ainda que os saberes tenham sido remodelados e as tecnologias gráficas avançado, o livro escolar, como objeto de estudo, tem historicidade e cumpre um papel específico em cada contexto.

Este estudo, ao colocar o livro escolar Educação Moral e Cívica de autoria do General Benedicto de Andrade (1978) na ordem daquele tempo e abordar seus projetos, concepções e mesmo rastrear em seus textos os encaminhamentos para uma construção de civilidades/sensibilidades, o fez mediante exercício de uma operação historiográfica: leu um passado que não existe mais através da produção 
de um discurso neste presente e projetou outras possibilidades de pesquisa que podem ser exploradas, sempre confrontadas com as lacunas da documentação.

\section{MÁRCIA REGINA DOS SANTOS}

Mestre em Educação pelo Programa de Pós-Graduação em Educação da Universidade do Estado de Santa Catarina (UDESC), na Linha de Pesquisa História e Historiografia da Educação.

\section{MARIA TERESA SANTOS CUNHA}

Doutora em Educação - História e Filosofia pela Universidade de São Paulo (USP). Professora do Programa de Pós-Graduação em Educação e do Programa de PósGraduação em História da Universidade do Estado de Santa Catarina (UDESC). Bolsista Produtividade em Pesquisa do CNPq.

\section{REFERÊNCIAS}

ANDRADE, B. Educação Moral e Cívica. 5.ed. revisada e aumentada. São Paulo: Atlas, 1978.

BASTOS, M. H. C. Pedagogias e Manuais: Leituras cruzadas - Os manuais de História da Educação adotados no Brasil (1870-1950). Porto Alegre, Texto impresso, 2010.

BITTENCOURT, C. Disciplinas escolares: História e pesquisa. In: OLIVEIRA, M. A. T.; RANZI, M. F. (Orgs.). História das disciplinas escolares no Brasil: contribuições para o debate. Bragança Paulista (SP): EDUSP, 2003. p. 9-18.

BRASIL. Decreto-Lei n 869 , de 12 de setembro de 1969. Dispõe sobre a inclusão da Educação Moral e Cívica como disciplina obrigatória, nas escolas de todos os graus e modalidades, dos sistemas de ensino no País, e dá outras providências. Disponível em:

http://legis.senado.gov.br/legislacao/ListaPublicacoes.action?id=195811. Acesso em: 23 fev. 2014.

CARVALHO, J. M. de. Cidadania no Brasil. O longo caminho. 18. ed. Rio de Janeiro: Civilização Brasileira, 2014. 
CASTILLO GÓMEZ, A. História de la Cultura Escrita. Madrid: Edicciones Trea, 2002.

CHARTIER. R. A História Cultural: Entre Práticas e Representações.Lisboa: DIFEL, 1989.

A mão do autor e a mente do editor. São Paulo: UNESP, 2014.

CHERVEL, A. História das disciplinas escolares: reflexões sobre um campo de pesquisa. Teoria \& Educação, n. 2, p. 177-229, 1990.

CHOPPIN, A. O historiador e o livro escolar. Revista História da Educação. Pelotas, n.11, p. 5-24, abr. 2002.

CUNHA, M. T. S. Um Patriotismo São: lições de História para a Escola Primária. Um estudo na série de leitura graduada "Pedrinho" de Lourenço Filho (décadas de 50/70 do século XX). Revista Linhas, Florianópolis, v. 12, n. 01, p. 154-169, jan./jun. 2011.

. Das mãos para as mentes. Protocolos de civilidade em um jornal escolar/SC 91945-1952). Educar em Revista, Curitiba, n. 49, p. 139-159, jul./set. 2013.

ELIAS, N. O Processo Civilizador. Volume 2: Formação do Estado e Civilização. Tradução da versão inglesa, Ruy Jungmann; revisão, apresentação e notas, Renato Janine Ribeiro. Rio de Janeiro: Jorge Zahar Editora, 1993.

FILGUEIRAS, J. M. O Livro Didático de Educação Moral e Cívica na Ditadura de 1964: A construção de uma disciplina. In: VI Congresso Luso Brasileiro De História Da Educação Percursos E Desafios Da Pesquisa E Do Ensino De História Da Educação, 6, 2006, Uberlândia. Anais. Uberlândia, Universidade Federal de Uberlândia (UFU), 2006. p. 3375-3385. Disponível em:

http://www2.faced.ufu.br/colubhe06/anais/arquivos/302JulianaMirandaFilgueiras.pdf . Acesso em: 20 mar. 2014.

FONSECA, S. G.; GATTI JR ,D. (Orgs.). Perspectivas do ensino de História: Ensino, Cidadania e Consciência Histórica. Uberlândia: EDUFU e FAPEMIG, 2011.

GATTI JR, D. A escrita escolar da História: livro didático e ensino no Brasil (19701990). Bauru/SP: Edusc, 2004.

JULIA, D. A cultura escolar como objeto histórico. Revista Brasileira de História da Educação. Maringá, n.1, p. 9- 43, jan./jun., 2001.

VIÑAO FRAGO, A. Sistemas educativos, culturas escolares e reformas. Portugal/ Mangualde: Edições Pedago, 2007. 